\title{
DISLEXIA NAS SÉRIES INICIAIS DO ENSINO FUNDAMENTAL: COMO FACILITAR O APRENDIZADO
}

\author{
Andréa Brasiliano Petronilo \\ Graduada em Letras - Português pela UnP e graduanda em Licenciatura em Espanhol no \\ Instituto Federal de Educação, Ciência e Tecnologia do Rio Grande do Norte-IFRN. \\ E-mail: deinha_bp@hotmail.com \\ Douglas Lima de Oliveira \\ Graduando em Licenciatura em Espanhol no Instituto Federal de Educação, Ciência e \\ Tecnologia do Rio Grande do Norte-IFRN. E-mail: douglaslo@ hotmail.com

\section{Lessandra Paula Targino de Oliveira} \\ Graduanda em Licenciatura em Espanhol no Instituto Federal de Educação, Ciência e \\ Tecnologia do Rio Grande do Norte-IFRN. E-mail: lessandrinha1 @ yahoo.com.br
}

\begin{abstract}
RESUMO
Mediante a necessidade de incluir alunos especiais na rede regular de ensino, nos propomos a falar acerca da dislexia, um dos distúrbios de aprendizagem. Esta pesquisa tem por objetivo discorrer sobre os métodos que, aplicados em sala de aula, contribuem para o processo de ensino/aprendizagem da criança disléxica nas séries iniciais do Ensino Fundamental. No decorrer da pesquisa, mostraremos as características mais comuns de uma criança que possui esse distúrbio de aprendizagem, falaremos sobre a importância do diagnóstico em sala de aula e, por fim, apresentaremos os métodos de apoio para contornar essas dificuldades específicas. A metodologia adotada no nosso Projeto foi a pesquisa bibliográfica, e em toda a pesquisa foram utilizados conceitos dos autores LANHEZ e NICO (2002) e LIMA, C. F.; CAMEIRÃO, M. L.; MEIRELES, L. P (2005), além dos conhecimentos adquiridos nas disciplinas do curso de Licenciatura em Espanhol. Acreditamos que este trabalho possa despertar o interesse pela inclusão escolar das crianças que apresentem uma dificuldade de aprendizagem como a dislexia.
\end{abstract}

PALAVRAS-CHAVE: dislexia, métodos, dificuldade de aprendizagem.

\section{DISLEXIA EN LAS PRIMERAS SERIES DE EDUCACIÓN BÁSICA: CÓMO FACILITAR EL APRENDIZAJE}

\section{RESUMEN}

Por la necesidad de incluir a los estudiantes especiales en el sistema educativo, nos proponemos hablar de dislexia, un trastorno del aprendizaje. Esta investigación tiene como objetivo discutir los métodos aplicados en el aula que contribuyen a la enseñanza y el aprendizaje de los niños disléxicos en los primeros grados de educación básica. Durante la investigación, vamos a mostrar las características más comunes de un niño con este trastorno de aprendizaje, vamos a hablar de la importancia del diagnóstico en el aula y, por último, vamos a presentar métodos para superar estas dificultades especiales. La metodología utilizada en nuestro proyecto fue una búsqueda en la literatura, y en todo el estudio se utilizaron los conceptos de los autores LANHEZ e NICO (2002) e LIMA, C. F.; CAMEIRÃO, M. L.; MEIRELES, L. P (2005), además de los conocimientos en las 
disciplinas de Licenciatura en español. Creemos que este trabajo va a despertar el interés en la escolarización de los niños que tengan dificultades de aprendizaje como la dislexia.

PALAVRAS CLAVE: dislexia, métodos, dificultades de aprendizaje. 


\section{DISLEXIA NAS SÉRIES INICIAIS DO ENSINO FUNDAMENTAL: COMO FACILITAR O APRENDIZADO}

\section{INTRODUÇÃO}

O interesse pelo assunto da dislexia surgiu a partir da observação de que ela vem sendo objeto de estudo e investigação de vários pesquisadores nos últimos anos dada a sua relevância na atualidade. De acordo com Lanhez e Nico (2002), antigamente pouco se falava sobre a dislexia, pois faltava conscientização por parte dos educadores e profissionais sobre os distúrbios de aprendizagem. Era muito comum o uso das expressões os "atrasados", os "deficientes" ou os "que não davam para o estudo". E assim a dislexia passou a estar entre os fatores que promovem o abandono escolar e geram a exclusão social. Ainda segundo as autoras, as pesquisas revelam que a incidência de dislexia é de $10 \%$ a $15 \%$ na população mundial, ou seja, em uma sala de aula com 25 alunos, cerca de três ou quatro crianças são disléxicas.

Então, quando tratamos da educação, é certo que precisamos conhecer as principais características dessa dificuldade de aprendizagem, pois no exercício da nossa profissão é bem provável que nos deparemos com um educando que apresente tal obstáculo na aquisição do conhecimento.

Apesar de fazermos uma descrição dos sintomas mais comuns desse distúrbio, facilitando, dessa forma, o diagnóstico do problema, a razão principal desta pesquisa é expor algumas metodologias que servem de apoio ao professor no exercício do seu trabalho. A presente pesquisa também está fundamentada na $\mathrm{LDB}$, art. $4^{\circ}$, inciso 3 , que garante "atendimento educacional especializado gratuito aos educandos com necessidades especiais, preferencialmente na rede regular de ensino" (LDB, 1996).

Com base nessas informações, nos propomos a mostrar que é possível ajudar um aluno disléxico a compreender e assimilar bem as matérias desde que haja preparação por parte do educador e escolha adequada de métodos para a exposição das matérias em sala de aula. Saber como lidar com um aluno disléxico e como incluí-lo no sistema educacional é primordial, pois "a falta de atenção adequada e o desconhecimento levam muitas das pessoas, consideradas desiguais, a se afastarem ou serem afastadas do ambiente escolar, acabando por se sujeitarem a ocupar posições menores na escala social" (LANHEZ e NICO, 2002, p. 09).

\section{O MODELO TEÓRICO DA DISLEXIA}

O primeiro passo a ser dado em direção a solução de um problema é correr em busca de sua definição. Conhecer o problema, então, é condição imprescindível para resolvê-lo. Por isso, colocaremos aqui duas definições de dislexia que consideramos as mais aceitáveis e que se reafirmam. Entretanto, antes das definições queremos expor a justificativa para o termo dislexia: DIS = distúrbio ou dificuldade; LEXIA = do latim "leitura" e/ou do grego "linguagem". Assim, DISLEXIA = distúrbio de linguagem (LANHEZ e NICO, 2002). É importante ressaltar que a denominação do problema feita aqui é somente para facilitar a identificação dele a fim de que a ajuda aos disléxicos possa ocorrer de forma adequada. Também queremos enfatizar ainda que existem dois tipos de dislexia: a de evolução e a adquirida, e nós discorreremos acerca da primeira, que é congênita e hereditária. A segunda advém como consequência de traumatismo craniano, acidente vascular, derrame etc. 
A primeira definição que apresentamos é a do dr. Samuel T. Orton encontrada na obra de LANHEZ e NICO (2002). Segundo ele, a dislexia, como o próprio termo indica, não se enquadra na situação de doença, mas de distúrbio: "É uma dificuldade no processo de leitura, escrita, soletração e ortografia. [...] Torna-se evidente na época da alfabetização, embora alguns sintomas já estejam presentes em fases anteriores" (ORTON apud LANHEZ e NICO, 2002, p. 21). Segundo essa definição, a criança não adquire a linguagem de forma correta, embora tenha inteligência suficiente e não apresente nenhum distúrbio cognitivo. Dessa forma, segundo o dr. Orton pode-se dizer que esse distúrbio não é causado por falha intelectual, emocional ou cultural, mas por hereditariedade. O curioso é que os geneticistas do comportamento mostram que há até $50 \%$ de probabilidade de um menino nascer disléxico se seu pai for disléxico, e cerca de $40 \%$ se a mãe for disléxica. Já a probabilidade de uma menina desenvolver essa afecção é um pouco menor, e o que é herdado, neste caso, não é a deficiência de leitura, mas sim o processo da linguagem.

A segunda definição que adotamos para a nossa pesquisa também se encontra na obra de Lanhez e Nico (2002), e é da International Dislexia Association, elaborada no Comitê de Abril de 1994. Segundo essa teoria, que é atualmente a mais usada nas pesquisas de neuroanatomia e neuropsicologia, dentre as várias dificuldades de aprendizagem, a dislexia é a que tem origem constitucional e é caracterizada pela dificuldade em decodificar palavras simples em uma idade em que isso não é mais aceitável. A criança apresenta uma insuficiência no processo fonológico e também um atraso na aquisição e uso da linguagem.

A dislexia também pode ser chamada de "dificuldade oculta" ou "dificuldade invisível", já que ela não está ligada a alterações físicas palpáveis. Estudos mostram que há uma pequena diferença na constituição cerebral de uma criança que apresenta essa dificuldade e outra que não apresenta. Entretanto, essa diferença é muito pequena e não pode ser detectada por técnicas de exames mais comuns.

Existe a possibilidade de que a dislexia possa ter uma causa cerebral, embora ainda haja muitas dúvidas quanto a essa questão. Mas foi constatado que o volume do lobo temporal direito é maior que o esquerdo, atribuindo, assim, a existência de uma base neurológica e biológica para o distúrbio. (LANHEZ e NICO, 2002).

\section{SINTOMAS MAIS COMUNS}

Segundo Snowling (2000) citado por Lima; Cameirão \& Meireles (2005), a linguagem escrita, apesar de ser uma aquisição relativamente recente do ponto de vista evolutivo, tornou-se fulcral no processo de transmissão sócio-cultural, sendo que ler e escrever são de competência das áreas cognitivas mais valorizadas e importantes que o sujeito pode adquirir. Apesar da complexidade deste processo, a maioria das crianças que recebe uma instrução adequada desenvolve-as com relativa facilidade. Não obstante, há uma minoria que apresenta dificuldades específicas no domínio da leitura, mesmo possuindo uma inteligência normal e apresentando mestria em outras tarefas.

Sabendo o que é a dislexia, devemos estar atentos aos seus sintomas, pois como profissionais da disciplina de Letras lidaremos diretamente com a questão da escrita, e é indispensável que saibamos identificar uma criança que apresente dificuldades nessa área. Listaremos alguns dos indícios mais comuns, mas tendo em mente que a dislexia só pode ser confirmada em crianças que, no mínimo, possuem inteligência média. Se o aluno apresentar inteligência abaixo do esperado, ele pode se enquadrar em outros tipos de dificuldades. 
Entre os sintomas mais comuns estão:

\begin{abstract}
Desempenho inconstante; demora na aquisição da leitura e da escrita; lentidão nas tarefas de leitura e escrita, mas não nas orais; dificuldade com os sons das palavras e, consequentemente, como a soletração; dificuldade em associar o som ao símbolo [...] desconforto ao tomar notas e/ou relutância para escrever; persistência no mesmo erro, embora conte com ajuda profissional. (LANHEZ e NICO, 2002, p. 2627).
\end{abstract}

Além destes, ainda queremos citar a dificuldade para organizar coisas que sigam uma sequiência (como, por exemplo, as letras do alfabeto, os meses do ano e a tabuada) e a dificuldade em se organizar. Segundo Lanhez e Nico (2002), a maioria desses sintomas listados está ligada à memória de curto prazo ou "memória imediata", e à memória seqüencial. A primeira é aquela vital para o processamento de leitura, pois permite guardar informações pelo período de tempo necessário para serem processadas corretamente. Como os disléxicos possuem falhas em relação à memória de curto prazo, há lentidão no processamento de leitura e compreensão de sentido de uma frase ou parágrafo. A segunda, a memória seqüencial, é a responsável pela própria organização mental. Por isso, muitas crianças disléxicas chegam atrasadas em encontros ou têm dificuldades para achar um endereço na lista telefônica, por exemplo.

A dificuldade observada na aprendizagem da leitura e da escrita e o fraco desempenho nos testes de leitura e de escrita pertencem ao nível do comportamento, enquanto as causas subjacentes a esse desempenho estão situadas no nível cognitivo - que também inclui fatores emocionais. O nível biológico refere-se a observações e fatos relacionados ao cérebro. Assim, a dislexia é uma desordem do desenvolvimento que deve ser explicada a partir de três origens: (1) biológica, que causa um déficit cognitivo, o qual, por sua vez, resulta em um padrão particular de comportamento; (2) uma anormalidade cerebral e (3) um déficit cognitivo. As influências ambientais são vistas como atuantes em todos esses três níveis (PINHEIRO, 2002).

É importante notar que indivíduos com dislexia podem apresentar também déficit em outras áreas cognitivas ou acadêmicas, como na matemática. Contudo, a dislexia é uma perturbação específica, na medida em que é possível diferenciar as características cognitivas associadas a déficit nas competências básicas de leitura das características cognitivas de outros déficits (LYON et al., 2003 apud LIMA; CAMEIRÃO \& MEIRELES, 2005). Os sintomas da dislexia podem se apresentar "de forma isolada ou combinada e, ainda, se combinarem de diferentes modos em cada disléxico" (LANHEZ e NICO, 2002, p. 27).

\title{
A IMPORTÂNCIA DA IDENTIFICAÇÃO DA DISLEXIA EM SALA DE AULA
}

Apesar de a dislexia não ser causada por fatores ambientais, o futuro da criança disléxica depende de forma imprescindível do meio. Como já dissemos na introdução deste trabalho, muitas pessoas, consideradas desiguais, se afastam ou são afastadas do ambiente escolar por não terem atenção adequada. O que muitos não sabem é que embora os disléxicos apresentem dificuldades no processo de leitura, escrita, soletração e ortografia, em geral eles possuem níveis de inteligência superiores e habilidades extraordinárias em determinadas áreas. Lanhez e Nico (2002) afirmam que isso significa dizer que, ao afastar essas crianças das salas de aulas, o país está desperdiçando talento e muita capacidade de produção, já que há cerca de $15 \%$ de disléxicos na população mundial, ou seja, um número bastante significativo. 
Portanto, uma educação que reconheça as dificuldades específicas destes alunos muito poderá contribuir para o seu desenvolvimento, associado a um tratamento interdisciplinar sendo, às vezes, necessário fazer uma eleição terapêutica, ou seja, priorizar um tratamento em um dado momento. A escola e a família exercem um papel fundamental para que a dislexia não se torne mais um fator de impedimento no crescimento acadêmico. Para Mousinho (2003), o professor também é indispensável neste caminho, identificando, em um primeiro momento, e podendo compreender e auxiliar essas crianças e jovens em seu processo educativo.

Daí a importância do professor saber fazer a identificação em sala de aula. É certo que não seremos especialistas no assunto, mas poderemos observar os comportamentos mais comuns e agir com mais cautela com aquele aluno. Segundo Lanhez e Nico (2002), o diagnóstico deve ser feito por uma equipe multidisciplinar formada por psicólogo, fonoaudiólogo e psicopedagogo e, quando é necessário, é feito um encaminhamento ao neurologista e/ou a outros profissionais como oftalmologista, geneticista, otorrinolaringologista e pediatra para determinar se existem ou não outros fatores que possam estar comprometendo o processo de aprendizagem, e todos os profissionais devem trocar informações para confirmar o distúrbio. Todo disléxico pode e deve ser ajudado, e entendendo as limitações do aluno, o trabalho deste e do professor será realizado com maior êxito.

As crianças com dislexia aprendem de maneira diferente, mas isso não significa que não aprendam. Elas podem acompanhar o ensino convencional se tiverem o apoio necessário para contornar suas dificuldades especificas. Normalmente, crianças disléxicas têm a necessidade de transportar o que estão aprendendo para o campo da realidade concreta, e geralmente os conteúdos são mais bem aprendidos quando apresentados de forma a estimular os sentidos de tato, paladar, visão e sensação (LANHEZ e NICO, 2002). O sucesso e aprovação que as crianças experimentam quando tentam se comunicar com os adultos os motiva muito no desenvolvimento da fala, e a maior parte aborda a leitura com a mesma ansiedade com que aprendem a falar. Aquelas que vacilam nos primeiros estágios precisam de orientação e apoio que vai lhes garantir êxito, e isso tem maior probabilidade de ocorrer se houver o envolvimento tanto do lar quanto da escola.

Para auxiliar o professor no trato aos disléxicos, algumas metodologias podem ser adotadas, ajudando no seu trabalho em sala de aula e facilitando o aprendizado do aluno. É o que veremos no próximo ponto.

\section{FACILITANDO A APRENDIZADO}

São princípios básicos do trabalho em linguagem escrita com a criança: estimular a descoberta e utilização da lógica de seu pensamento na construção de palavras e textos e na representação de fonemas; oferecer oportunidades para a escrita e leitura espontâneas; explorar constantemente as diversas funções da escrita (não apenas produção textual, mas também cartas e bilhetes); e explicitar as diferenças entre língua falada e língua escrita. É importante que a criança tenha adequada consciência de que a fala e a escrita são formas diferentes de expressão da linguagem. A principal indicação atual para o tratamento de crianças com dificuldades de linguagem escrita é a intervenção direta nas habilidades de leitura, associada a atividades relacionadas ao processamento fonológico da linguagem. Práticas anteriores buscavam estimular habilidades consideradas pré-requisitos para o aprendizado da leitura, como percepção visuoespacial e habilidades psicomotoras (SCHIRMER et al., 2004). E como trabalhar com crianças que não conseguem assimilar o conteúdo dentro do tempo considerado necessário para que as informações sejam processadas corretamente? 
As dificuldades verificadas na dislexia são muitas vezes inesperadas, especialmente quando se considera o nível de outras capacidades cognitivas e a existência de uma instrução adequada. A história de instrução do indivíduo é um aspecto crítico para a compreensão da natureza das dificuldades de leitura observadas. Muitas crianças correm o risco de falharem na leitura devido a desvantagens ao nível da educação na primeira infância e das experiências na préescola. Deste modo, entram frequentemente na escola sem terem adquirido muitas capacidades linguísticas e de "pré leitura" essenciais (e.g., sensibilidade fonológica, vocabulário), fundamentais para um desenvolvimento normal da leitura. Se a instrução não for ajustada ao ensino das competências que a criança não domina, a falha na leitura ocorrerá frequentemente. (LYON et al., 2003 apud LIMA; CAMEIRÃO \& MEIRELES, 2005).

Então, devidamente ciente da situação de dificuldade de aprendizagem do aluno, o professor deve estar preparado para utilizar variedade e flexibilidade no seu estilo de ensino. Alguns métodos encontrados na obra de Lanhez e Nico (2002) foram observados e depois selecionados especialmente para este trabalho. É sobre eles que passaremos a discorrer agora (obs.: a enumeração foi feita a título de organização apenas, e não em ordem de prioridades).

1. Conversa individual - é importante que o professor, no primeiro dia de aula, deixe claro para o aluno especial sobre seu desejo de manter contato individual com ele facilitando, assim, o seu aprendizado e abrindo caminho para que o aluno se sinta a vontade para tirar suas dúvidas.

2. Esquema de aula - para que o aluno se organize mentalmente quanto às matérias, é bom o professor iniciar cada módulo com um esquema da aula e finalizar retomando-o e destacando os pontos-chave.

3. Variedade de recursos em sala de aula - como as crianças disléxicas sentem dificuldade para ler e interpretar textos, os conteúdos serão mais bem aprendidos se apresentados de forma a estimular os sentidos de tato, paladar, visão e sensação. Portanto, além dos livros trabalhe também com apresentação de slides, filmes educativos e outros recursos multimídia. Não espere que uma criança com dificuldades de leitura obtenha toda informação por meio de textos.

4. Evite ditados - mesmo que as crianças se lembrem das palavras oralmente, provavelmente as esquecerá em curto espaço de tempo e terá muita dificuldade em escrevê-las.

5. Evite dar instruções orais e escritas ao mesmo tempo - esse estilo de informar pode gerar confusão na cabeça do aluno. Ele ficará dividido entre ouvir e copiar.

6. Estimule-a a olhar as palavras - permita que a criança observe detalhadamente cada letra que forma uma palavra, mas utilize poucas letras de cada vez. Uma dica é a utilização do jogo da memória, quando possível, para estimular a observação cuidadosa e a lembrança precisa.

7. Dê aulas de revisão - é provável que o aluno disléxico fique intimidado diante dos colegas e não tenha coragem de dizer que não entendeu (ou não lembra) da matéria. Assim, realize aulas que retomem o que já foi visto em sala para que esse aluno possa tirar suas dúvidas.

8. Permita o uso de tabuadas e calculadoras simples - isso porque na matemática muitos alunos disléxicos têm problemas na realização dos cálculos por não conseguirem memorizar a tabuada ou por confundir os sinais de mais (+) e vezes (x), menos (-) e igual (=) etc. 
9. Use avaliações orais - por apresentar dificuldades de soletração e escrita, o aluno com dislexia é bem mais sucedido em atividades orais. Então, cada professor deve entender que as respostas orais dos alunos disléxicos são indicações melhores de suas habilidades.

10. Permita que o aluno erre - isso fará com que ela se sinta mais livre para se expressar e mais interessada em corrigir o erro. Evite comentar muito a falha dela, pois todo deslize muito comentado faz com que a autoconfiança de qualquer pessoa diminua. Ao contrário, use o erro de forma construtiva ajudando no processo de aprendizagem

11. Dê prazos de entrega de trabalho maiores - já que a criança disléxica tem falhas na memória sequiencial, é compreensível que ela tenha dificuldade em organizar seu tempo. Por isso, dê um prazo para que ela possa trabalhar no seu próprio ritmo e conforme seus interesses e habilidades.

12. Não a force a ler em voz alta para a turma - existe uma dificuldade frequente em pronunciar algumas palavras, por isso possibilite que ela leia em voz alta somente se concordar com a ideia.

13. Nunca a chame de preguiçosa ou desleixada - a criança disléxica realmente apresenta dificuldades em organizar-se. Entretanto, o que pode ser observado também é se ela está desestimulada devido algum fracasso que tenha vivido.

Dentre os cuidados que a escola deve ter em relação aos disléxicos, ainda queremos destacar que é seu papel: dar encorajamento ao aluno especial; atender e respeitar as capacidades e os limites dessa criança; estar informada para amparar o aluno em sua dificuldade; manter o(s) professor(es) familiarizado(s) e sensibilizado(s) com a dislexia para compreender e apoiar na sala de aula e ainda reconhecer a necessidade de ajuda; e, por fim, desenvolver um clima de paciência extra para que a criança tenha tempo de cumprir sua tarefa e até mesmo repeti-la varias vezes.

Há muitas outras formas de ajudar um aluno que apresente a dislexia ou qualquer outro tipo de dificuldade de aprendizagem. Entretanto, em suma, o principal é que a criança interaja normalmente com os demais colegas e tenha um professor que compreenda seus problemas. Caso o professor se sinta despreparado para ajudar o aluno, ele deve solicitar a ajuda de outros profissionais, como psicólogos, fonoaudiólogos e psicopedagogos para a devida orientação de como trabalhar com aquele aluno dentro e fora de sala de aula.

O educador também deve ter em mente que o estudante disléxico enfrenta muitos fracassos e algumas tarefas impossíveis durante a aula. Por isso, é importante que o professor considere os pequenos avanços que o aluno demonstrar, pois essa apreciação estabelecerá uma certa autoconfiança. Quando o professor interessa-se pelo aluno como pessoa, eleva a auto-estima dele.

Em suma, é preferencial que todas as atividades de estimulação da linguagem escrita nas séries iniciais do Ensino Fundamental sejam realizadas de forma lúdica, através de jogos e brincadeiras, para que a criança sinta prazer em ler e escrever. 


\section{CONSIDERAÇÕES FINAIS}

Neste trabalho procuramos expor os métodos que facilitam o trabalho do professor e a aprendizagem do aluno disléxico das séries iniciais do Ensino Fundamental, onde é mais provável o contato com esses alunos. Propomos-nos a mostrar que é possível ajudar o aluno a compreender e assimilar bem as matérias desde que haja preparação por parte do educador.

Embora no Brasil ainda não exista uma legislação específica para a dislexia, em termos educacionais, sabemos que as leis prevêem várias das ações que aqui foram sugeridas. Para finalizar, citaremos uma dessas leis, além da já citada na introdução do nosso trabalho:

[...] a criança e o adolescente têm direito à educação, visando ao pleno desenvolvimento de sua pessoa, preparo para o exercício da cidadania e qualificação para o trabalho, assegurando-lhes: I - igualdade de condições para acesso e permanência na escola; II - direito de ser respeitado pelos seus educadores; III - direito de contestar critérios avaliativos, podendo recorrer às instâncias escolares superiores. (Lei 8.069, de 13 de julho de 1990 (ECA) Artigos 53, incisos I, II, e III apud LANHEZ e NICO, 2002).

Dessa afirmação podemos entender que garantir o acesso do aluno à escola é dever da instituição governamental, mas a permanência dele no ambiente escolar tanto depende do governo quanto da própria escola e da atuação do professor em sala de aula apoiado também pelos pais desse aluno. E se a criança apresentar alguma necessidade especial, mais preparação vai ser requerida do educador. O compromisso da escola não é somente ensinar, mas proporcionar meios para a aprendizagem; e para haver aprendizagem por parte dos alunos que têm algum distúrbio, muito tempo e recursos devem ser desprendidos. O trabalho só pode ser considerado acabado quando todos os alunos aprenderem.

Esperamos que nossa pesquisa tenha contribuído para o esclarecimento e melhor compreensão de algumas questões sobre a dislexia, e que também sirva como gerador de discussões sobre o assunto e reflexões sobre a prática dos docentes em sala de aula. O que expusemos aqui nesta pesquisa mostra a preocupação que temos em estar em constante aperfeiçoamento enquanto profissionais da área de licenciatura. Este estudo nos permitiu concluir que não é simples o trabalho do educador em incluir um aluno especial no sistema de ensino, mas nem por isso a tarefa chega a ser impossível mesmo no caso da dislexia, em que as dificuldades persistem mesmo quando a instrução é apropriada.

\section{REFERÊNCIAS}

1. BRASIL. Lei $\mathrm{N}^{\circ}$ 9.394, de 20/12/96: LDB. Estabelece as diretrizes e bases da Educação Nacional. Brasília, DF, 1996.

2. MOUSINHO, R. Conhecendo a dislexia. Revista Sinpro (Ed. Especial.): 26-33, 2003.

3. LANHEZ, Maria Eugência; NICO, Maria Angela. Nem sempre é o que parece: como enfrentar a dislexia e os fracassos escolares. 11 ed.. Rio de Janeiro: Elseiver, 2002.

4. LIMA, C. F.; CAMEIRÃO, M. L.; MEIRELES, L. P. Dislexia no $\mathbf{1}^{\mathbf{0}}$ ciclo: Da actualidade científica às concepções dos professores. Trabalho de licenciatura. Portugal, 2005.

5. PINHEIRO, A. M. V. Dislexia do desenvolvimento: perspectivas cognitivoneuropsicologicas. Athos \& Ethos. Volume 2, 2002. 
6. SCHIRMER, C. R. et al., Distúrbios da aquisição da linguagem e da aprendizagem. Jornal de pediatria. V.80(2): S95-S103, 2004. 